\title{
Penggunaan Model Regresi untuk Memprediksi Arus Lalu Lintas Laut yang Berdampak pada Kebutuhan Fasilitas Pelabuhan (Studi Kasus : Pelabuhan Yos Sudarso Ambon)
}

\author{
Henriette Dorothy Titaley ${ }^{1}$ \\ 1Jurusan Teknik Sipil, Politeknik Negeri Ambon, hd_titaley@yahoo.com
}

\begin{abstract}
Abstrak
Ramalan atau prediksi pada dasarnya merupakan dugaan atau perkiraan akan terjadi suatu peristiwa yang akan datang. Dari hasil uji regresi diperoleh tingkat pertumbuhan pendudukan, pendapatan per kapita dan produk domestik regional bruto memiliki hubungan yang kuat (nilai korelasi antara $0,7-1,0$ ) terhadap jumlah arus penumpang, kapal dan barang. Peningkatan arus lalu lintas laut ini berdampak pada daya tampung fasilitas pelabuhan. Hasil analisis menunjukkan bahwa kondisi fasilitas pelabuhan ditinjau dari kelayakan teknis untuk jangka pendek sudah tidak memadai dan perlu pengembangan.
\end{abstract}

Kata Kunci : Arus Lalu Lintas Laut, Fasilitas Pelabuhan, Model Regresi, Prediksi

\section{The Use of Regression Model to Predict the Flow of Marine Traffic that Impact on the Needs of the Port Facility (Case Study : Yos Sudarso Port of Ambon)}

\begin{abstract}
Forecasts or predictions basically an allegation or estimates there will be an events that will come. Regression analysis showed that the rate of population growth, per capita income dan gross regional domestic product has a strong relationship (correlation values between 0,7-1,0) to the number of passengers flow, goods and ships. Increased marine traffic has an impact on the capacity of the port facility. Results of the analysis showed the condition of the port facility if the review of the technical feasibility for short term has been inadequate and need development.
\end{abstract}

Key words: Flow of Marine Traffic, Port Facility, Regression Model, Prediction

\section{Pendahuluan}

Peramalan nilai suatu variabel atau beberapa variabel pada masa yang akan datang sangat diperlukan sebagai dasar atau pedoman dalam pembuatan rencana yang menyangkut masa datang. Untuk pengembangan suatu pelabuhan, angka-angka prediksi mengenai arus lalu lintas angkutan barang dan penumpang di masing-masing wilayah sangat diperlukan untuk digunakan sebagai dasar dalam memperkirakan jumlah dan kapasitas kapal yang harus tersedia, fasilitas pelabuhan dan lain-lain. Kesalahan yang terjadi dalam perencanaan jumlah dan kapasitas kapal dapat mengakibatkan timbulnya masalah seperti terjadinya kelebihan kapasitas (over capacity) dan kekurangan kapasitas (under capacity). Oleh karena itu kemungkinan terjadinya perlu ditekan seminim mungkin melalui upaya peramalan (forecasting).

\section{Prediksi Arus Lalu Lintas Laut}

Data arus lalu lintas lalu lintas laut (arus penumpang, barang dan kapal) antar pelabuhan dari tahun-tahun sebelumnya merupakan informasi untuk meramalkan arus lalu lintas antar pelabuhan pada tahun yang akan datang. Untuk meramalkan jumlah arus penumpang, barang dan kapal dipakai metode proyeksi trend dengan analisa regresi. Dari garis trend tersebut akan diperoleh gambaran perkembangan arus barang, penumpang dan kapal di masa mendatang [1]. 


\section{Model Regresi}

Persamaan regresi digunakan untuk menggambarkan pola atau fungsi hubungan yang terdapat antar variabel. Persamaan model regresi berganda dirumuskan dengan, dimana, dan merupakan variabel bebas dan adalah variabel terikat (data prediksi), variabel $\mathrm{b}$ merupakan dugaan bagi parameter konstanta. Variabel yang akan diestimasi nilainya disebut variabel terikat (dependent variable atau response variable) dan variabel yang diasumsikan memberikan pengaruh terhadap variasi variabel terikat disebut variabel bebas (independent variable atau explanatory variable) [2].

\section{Pengujian Hipotesis}

Pengujian hipotesis dilakukan untuk mengetahui seberapa kuat hubungan antara variabel dependent dan independent dengan menggunakan uji $\mathrm{F}$ (simultan) dan uji $\mathrm{T}$ (parsial). Kriteria pengujian ditentukan sebagai berikut [3]:

1. Formula hipotesa : tidak ada pengaruh variabel independent terhadap variabel dependent secara simultan dan parsial.

: ada pengaruh variabel independent terhadap variabel dependent secara simultan dan parsial.

2. Derajat kepercayaan ditentukan sebesar $95 \%$ ().

3. Nilai signifikan: jika sig $>0,05$ maka diterima ditolak; jika sig $<0,05$ maka ditolak diterima.

\section{Peranan Pelabuhan dalam Pembangunan Ekonomi}

Keberadaan pelabuhan masa kini dan yang akan datang tetap saja dibutuhkan dalam pembangunan ekonomi regional maupun internasional. Pembangunan ekonomi akan mandek apabila aktifitas pelabuhan kurang berjalan normal sebagaimana fungsinya [4].

\section{Fasilitas Pelabuhan}

Fasilitas pelabuhan pada dasarnya dibedakan atas dua bagian besar yaitu sisi laut dan sisi darat. Fasilitas sisi laut berupa alur pelayaran, kolam pelabuhan dan dermaga. Kedalaman kolam pelabuhan ini direncanakan berdasarkan sarat (draft) dari kapal yang terbesar. Dimensi dermaga didasarkan pada jenis dan ukuran kapal yang merapat dan bertambat pada dermaga tersebut [5]. Perencanaan dermaga dipengaruhi oleh working days, produksi rata-rata per gang per jam, jumlah rata-rata jam kerja per hari, jumlah gang per kapal per tambatan, berth occupancy ratio (BOR). Kerja maksimum dapat dicapai apabila semua fasilitas tambatan yang ada dapat bermanfaat $100 \%$ occupancy, hal mana mengakibatkan waktu tunggu yang lebih lama. Fasilitas sisi darat berupa terminal penumpang, gudang, lapangan penumpukan, peralatan bongkar muat barang seperti forklift, mobil crane, truk dan lain-lain serta fasilitas perkantoran lainnya [6].

\section{Gambaran Umum Pelabuhan Yos Sudarso}

Secara geografis, Pelabuhan Yos Sudarso Ambon berada pada koordinat 0341’31” LS dan $128^{\circ} 10^{\prime} 28^{\prime \prime}$ BT da terletak pada wilayah administrasi kota Ambon. Dengan perbandingan luas lautan dan daratan adalah 9: 1 maka laut memegang peranan penting dalam hubungan antar wilayah. Sehingga pelabuhan Yos Sudarso Ambon dapat dijadikan sebagai pintu gerbang perekomunian dan pemerintahan Propinsi Maluku. pelabuhan Yos Sudarso adalah termasuk pelabuhan alam, karena tidak lagi dibangun breakwater untuk menjamin keamanan kapal dalam melakukan bongkar muat, karena pelabuhan ini terletak di dalam sebuah teluk yakni teluk Ambon sehingga daerah pelabuhan aman terhadap pengaruh angin dan gelombang laut di sekelilingnya

\section{Metodologi Penelitian}

Metode yang digunakan adalah studi literatur dan studi lapangan dengan tahapan:

a. Meninjau kondisi eksisting pelabuhan.

b. Mengumpulkan data arus lalu lintas laut (data arus penumpang, data arus barang, data kunjungan kapal) selama 15 tahun terakhir (2000-2014), PDRB Maluku, pertumbuhan penduduk Maluku dan pendapatan per kapita daerah Maluku. 
c. Melakukan peramalan arus lalu lintas laut untuk beberapa tahun ke depan dengan menggunakan analisis regresi linier berganda.

d. Melakukan evaluasi terhadap kondisi fasilitas pelabuhan untuk jangka pendek.

\section{Hasil dan Pembahasan}

Arus penumpang, kapal dan barang di Pelabuhan Yos Sudarso menunjukkan tendensi yang terus meningkat tiap tahun (gambar 1).

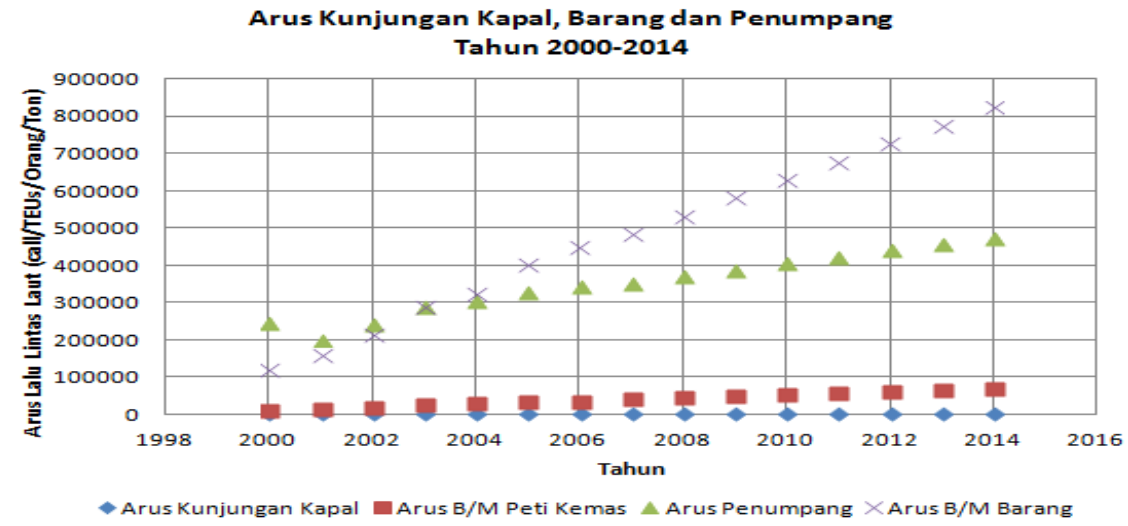

Gambar 1. Arus lalu lintas laut di Pelabuhan Yos Sudarso

\subsection{Uji Regresi}

Pengujian dilakukan pada arus lalu lintas laut di pelabuhan Yos Sudarso dan hubungannya dengan pertumbuhan ekonomi daerah.

Tabel 1. Uji regresi pada arus barang

$\operatorname{ANOVA}(\mathbf{b})$

\begin{tabular}{|ll|r|r|r|r|c|}
\hline \multicolumn{1}{|c|}{ Model } & \multicolumn{1}{|c|}{ Sum of Squares } & \multicolumn{1}{c|}{ Df } & \multicolumn{1}{c|}{ Mean Square } & \multicolumn{1}{c|}{ F } & Sig. \\
\hline 1 & Regression & 710317929376,928 & 2 & 355158964688,464 & 70,782 &, $000(\mathrm{a})$ \\
& Residual & 1820719404,006 & 12 & 151726617,000 & & \\
Total & 712138648780,934 & 14 & & & \\
\hline
\end{tabular}

a Predictors: (Constant), Pendapatan_Per_Kapita, Pertumbuhan_Penduduk b Dependent Variable: Arus_Barang Coefficients(a)

\begin{tabular}{|c|c|c|c|c|c|}
\hline \multirow[t]{2}{*}{ Model } & \multicolumn{2}{|c|}{$\begin{array}{l}\text { Unstandardized } \\
\text { Coefficients }\end{array}$} & \multirow{2}{*}{$\begin{array}{c}\text { Standardized } \\
\text { Coefficients } \\
\text { Beta } \\
\end{array}$} & \multirow{2}{*}{ B } & \multirow{2}{*}{$\begin{array}{c}\text { Sig. } \\
\text { Std. Error }\end{array}$} \\
\hline & $\mathrm{B}$ & Std. Error & & & \\
\hline (Constant) & $-1315422,888$ & 437482,200 & & $-3,007$ & 011 \\
\hline Pertumbuhan_Penduduk & 847 & ,387 & ,224 & 2,189 & 049 \\
\hline Pendapatan_Per_Kapita & 189 & 025 & ,776 & 7,574 & 000 \\
\hline
\end{tabular}

a Dependent Variable: Arus_Barang

Dari tabel 1, nilai sig f hitung adalah $0,000<0,05$ menunjukan bahwa dugaan ditolak. Sig t hitung untuk pertumbuhan penduduk dan PDRB masing-masing 0,000 dan 0,049 $<0,05$ maka ditolak. Ini berarti bahwa pertumbuhan penduduk dan PDRB mempengaruhi arus barang baik secara simultan maupun parsial dengan nilai $\mathrm{r}=0,999$.

Dari tabel 2, nilai $\mathrm{F}$ sebesar 53,74 angka signifikan $0,000<0,05$ maka dugaan ditolak. Untuk tabel kedua, angka signifikan pertumbuhan penduduk sebesar 0,041 maka dugaan ditolak, nilai sig t hitung pendapatan per kapita sebesar 0,373 maka dugaan diterima. Ini berarti bahwa pendapatan per kapita tidak berpengaruh terhadap arus penumpang sebaliknya pertumbuhan penduduk berpengaruh terhadap arus penumpang. 
Tabel 2. Uji regresi pada arus penumpang

ANOVA

\begin{tabular}{|c|c|c|c|c|c|}
\hline \multirow[t]{2}{*}{ Model } & & & & \multirow[b]{2}{*}{$\mathrm{F}$} & \multirow[b]{2}{*}{ Sig. } \\
\hline & Sum of Squares & Df & Mean Square & & \\
\hline 1 Regression & 94276371628,243 & 2 & 47138185814,122 & 53,740 & ,000(a) \\
\hline Residual & 2229278717,090 & 12 & 185773226,424 & & \\
\hline Total & 96505650345,333 & 14 & & & \\
\hline
\end{tabular}

a Predictors: (Constant), Pendapatan_Per_Kapita, Pertumbuhan_Penduduk b Dependent Variable: Arus_Penumpang Coefficients

\begin{tabular}{|rl|r|r|r|r|r|}
\hline \multirow{2}{*}{ Model } & \multicolumn{2}{|c|}{$\begin{array}{c}\text { Unstandardized } \\
\text { Coefficients }\end{array}$} & $\begin{array}{c}\text { Standardized } \\
\text { Coefficients }\end{array}$ & \multicolumn{1}{c|}{ t } & \multicolumn{1}{c|}{ Sig. } \\
\hline & \multicolumn{2}{|r|}{ B } & \multicolumn{1}{c|}{ Std. Error } & Beta & B & Std. Error \\
\hline 1 & (Constant) & $-1057475,649$ & 484084,371 & & $-2,184$ &, 049 \\
& Pertumbuhan_Penduduk &, 980 &, 428 &, 705 & 2,290 &, 041 \\
& Pendapatan_Per_Kapita &, 026 &, 028 &, 285 &, 926 &, 373 \\
\hline
\end{tabular}

a Dependent Variable: Arus_Penumpang

Analisis dilakukan lagi dengan variabel independent yaitu pertumbuhan penduduk (tabel 3). Persamaan dapat diperoleh dengan nilai $r=0,988$.

Tabel 3. Uji regresi pada pertumbuhan penduduk

Model Summary

\begin{tabular}{|l|r|r|r|r|}
\hline Model & \multicolumn{1}{|c|}{ R } & R Square & Adjusted R Square & Std. Error of the Estimate \\
\hline 1 &, $988(a)$ &, 975 &, 973 & 13554,64665 \\
\hline
\end{tabular}

a Predictors: (Constant), Pertumbuhan_Penduduk

Coefficients(a)

\begin{tabular}{|c|c|c|c|c|c|}
\hline \multirow[t]{2}{*}{ Model } & \multicolumn{2}{|c|}{ Unstandardized Coefficients } & \multirow{2}{*}{$\begin{array}{c}\text { Standardized } \\
\text { Coefficients } \\
\text { Beta }\end{array}$} & \multirow{2}{*}{$\mathrm{t}$} & \multirow{2}{*}{$\begin{array}{c}\text { Sig. } \\
\text { Std. Error }\end{array}$} \\
\hline & $\mathrm{B}$ & Std. Error & & & \\
\hline $\begin{array}{ll}1 & \text { (Constant) } \\
& \text { Pertumbuhan_Penduduk }\end{array}$ & $\begin{array}{r}-1499050,885 \\
1,372\end{array}$ & $\begin{array}{r}81942,264 \\
, 061\end{array}$ & ,988 & $\begin{array}{r}-18,294 \\
22,633\end{array}$ & $\begin{array}{l}, 000 \\
, 000\end{array}$ \\
\hline
\end{tabular}

a Dependent Variable: Arus_Penumpang

Tabel 4. Uji regresi pada arus kunjungan kapal

ANOVA

\begin{tabular}{|ll|r|r|r|r|r|}
\hline \multicolumn{1}{|c|}{ Model } & \multicolumn{1}{c|}{ Sum of Squares } & \multicolumn{1}{c|}{ Df } & Mean Square & \multicolumn{1}{c|}{ F } & \multicolumn{1}{c|}{ Sig. } \\
\hline 1 & Regression & 12513748,945 & 2 & 6256874,473 & 63,455 &, $000(\mathrm{a})$ \\
& Residual & 1183245,988 & 12 & 98603,832 & & \\
& Total & 13696994,933 & 14 & & & \\
\hline
\end{tabular}

a Predictors: (Constant), Arus_Penumpang, Arus_Barang $\quad$ b Dependent Variable: Arus_Kunjungan_Kapal Coefficients(a)

\begin{tabular}{|rl|r|r|r|r|r|}
\hline \multirow{2}{*}{ Model } & \multicolumn{2}{|c|}{$\begin{array}{c}\text { Unstandardized } \\
\text { Coefficients }\end{array}$} & $\begin{array}{c}\text { Standardized } \\
\text { Coefficients }\end{array}$ & $\mathrm{T}$ & Sig. \\
\cline { 2 - 7 } & \multicolumn{1}{|c|}{ B } & \multicolumn{1}{c|}{ Std. Error } & Beta & B & \multicolumn{1}{c|}{ Std. Error } \\
\hline 1 & (Constant) & 5376,181 & 1225,229 & & 4,388 &, 001 \\
& Arus_Barang &, 010 &, 002 & 2,363 & 4,183 &, 001 \\
& Arus_Penumpang &,- 017 &, 007 & $-1,449$ & $-2,565$ &, 025 \\
\hline
\end{tabular}

a Dependent Variable: Arus_Kunjungan_Kapal

Dari tabel 4 memperlihatkan nilai $\mathrm{F}$ sebesar 63,455 dengan signifikan 0,000 dengan perbandingan tingkat signifikan sebesar 95\% (), maka dugaan ditolak. Selanjutnya tabel berikut menunjukkan angka signifikan untuk arus barang sebesar 0,01 dan arus penumpang sebesar 0,025 maka dugaan ditolak. Ini berarti bahwa arus barang dan arus penumpang berpengaruh terhadap arus kunjungan kapal dengan nilai $r=0,956$. 
Tabel 5. Uji regresi pada arus peti kemas

ANOVA(b)

\begin{tabular}{|c|c|c|c|c|c|}
\hline Model & Sum of Squares & $\mathrm{df}$ & Mean Square & $\mathrm{F}$ & Sig. \\
\hline 1 Regression & 5130788991,509 & 2 & 2565394495,754 & 285,586 &, $000(a)$ \\
\hline Residual & 107794942,224 & 12 & 8982911,852 & & \\
\hline Total & 5238583933,733 & 14 & & & \\
\hline
\end{tabular}

a Predictors: (Constant), PDRB, Pertumbuhan_Penduduk b Dependent Variable: Arus_Peti_Kemas Coefficients(a)

\begin{tabular}{|ll|r|r|r|r|r|}
\hline \multirow{2}{*}{ Model } & \multicolumn{2}{c|}{$\begin{array}{c}\text { Unstandardized } \\
\text { Coefficients }\end{array}$} & $\begin{array}{c}\text { Standardized } \\
\text { Coefficients }\end{array}$ & $\mathrm{t}$ & \multicolumn{1}{c|}{ Sig. } \\
\hline & \multicolumn{2}{|c|}{ B } & Std. Error & Beta & B & Std. Error \\
\hline 1 & (Constant) & $-248789,857$ & 65726,880 & & $-3,785$ &, 003 \\
& Pertumbuhan_Penduduk &, 204 &, 054 &, 631 & 3,762 &, 003 \\
& PDRB &, 003 &, 001 &, 366 & 2,178 &, 049 \\
\hline
\end{tabular}

a Dependent Variable: Arus_Peti_Kemas

Dari tabel 5, sig $\mathrm{f}$ hitung sebesar $0,000<0,05$, berarti bahwa dugaan ditolak. Selanjutnya masing-masing angka signifikan untuk pertumbuhan penduduk sebesar 0,003 dan PDRB sebesar 0,049 maka ditolak. Ini berarti bahwa pertumbuhan penduduk dan PDRB berpengaruh terhadap arus peti kemas dengan nilai $r=0,990$.

\subsection{Prediksi Arus Penumpang, Kapal dan Barang}

Prediksi arus barang (general cargo), peti kemas (container), penumpang dan kapal ditetapkan berdasarkan pada analisa secara matematis dari data time series pada tahun sebelumnya. Hasil prediksi menunjukkan kenaikan untuk pertambahan tahun (tabel 6).

Tabel 6. Hasil prediksi arus penumpang, kapal dan barang di pelabuhan Yos Sudarso

\begin{tabular}{|c|c|c|c|c|c|c|c|c|}
\hline \multirow{2}{*}{ Tahun } & \multicolumn{3}{|c|}{ Arus Penumpang (orang) } & \multirow{2}{*}{$\begin{array}{c}\text { Arus } \\
\text { Kunjungan } \\
\text { Kapal (call) }\end{array}$} & \multicolumn{3}{|c|}{ Arus Barang (ton) } & \multirow{2}{*}{$\begin{array}{c}\text { Arus B/M } \\
\text { Peti Kemas } \\
\text { (TEUs) }\end{array}$} \\
\hline & Turun & Naik & Total & & Bongkar & Muat & Total & \\
\hline 2015 & 217925 & 280916 & 498841 & 5308 & 851665 & 55637 & 907302 & 82248 \\
\hline 2020 & 247598 & 326497 & 574095 & 5630 & 1132189 & 57631 & 1189820 & 109041 \\
\hline
\end{tabular}

\subsection{Analisa Kebutuhan Fasilitas Pelabuhan}

Berdasarkan data arus lalu lintas penumpang, barang dan kapal dan kaitannya dengan pertumbuhan penduduk, pendapatan regional per kapita dan PDRB, maka kebutuhan fasilitas pelabuhan dapat dianalisa dengan memperhitungkan variabel-variabel yang terkait (tabel 7).

Tabel 7. Variabel Dan Data Analisis Kebutuhan Fasilitas Pelabuhan

\begin{tabular}{|l|l|}
\hline \multicolumn{1}{|c|}{ Variabel } & \multicolumn{1}{c|}{ Data } \\
\hline $\begin{array}{l}\text { Jumlah arus penumpang, barang } \\
\text { dan kapal, pertumbuhan penduduk, } \\
\text { pendapatan regional per kapita dan } \\
\text { produk domestik regional bruto }\end{array}$ & $\begin{array}{l}\text { Jumlah penumpang yang keluar masuk per tahun, jumlah kapal yang } \\
\text { keluar masuk per tahun, jumlah barang yang keluar masuk per tahun, } \\
\text { jumlah pertumbuhan penduduk per tahun, pendapatan regional per } \\
\text { tahun, produk domestik regional bruto per tahun }\end{array}$ \\
\hline $\begin{array}{l}\text { Dermaga } \\
\text { Gudang } \\
\text { Terminal penumpang } \\
\text { Lapangan penumpukan }\end{array}$ & $\begin{array}{l}\text { Panjang dermaga, cargo flow, produktivitas bongkar muat/jam } \\
\text { Luas gudang, cargo flow, tinggi penimbunan } \\
\text { Luas terminal, jumlah penumpang tiap tahun } \\
\text { Luas lapangan penumpukan, cargo flow, lamanya penimbunan }\end{array}$ \\
\hline Kapasitas alat bongkar muat & $\begin{array}{l}\text { Jumlah arus bongkar muat/tahun, efektifitas alat, jumlah jam kerja } \\
\text { sehari }\end{array}$ \\
\hline
\end{tabular}

Berdasarkan tabel 8, hasil analisa kebutuhan fasilitas pelabuhan menunjukkan bahwa kondisi fasilitas pelabuhan ditinjau dari kelayakan teknis sudah tidak memadai dan perlu pengembangan. 
Tabel 8. Hasil Analisa Kebutuhan Fasilitas Pelabuhan

\begin{tabular}{|c|l|c|c|c|}
\hline No. & \multicolumn{1}{|c|}{ Nama Fasilitas } & Tersedia & $\begin{array}{c}\text { Kebutuhan } \\
\text { Tahun 2015 }\end{array}$ & $\begin{array}{c}\text { Kebutuhan } \\
\text { Tahun 2020 }\end{array}$ \\
\hline 1. & $\begin{array}{l}\text { Dermaga: } \\
\text { - Jumlah tambatan } \\
\text { - Panjang dermaga }\end{array}$ & $\begin{array}{c}\text { tambatan } \\
576 \mathrm{~m}\end{array}$ & $\begin{array}{c}5 \text { tambatan } \\
164 \mathrm{~m}\end{array}$ & $\begin{array}{c}6 \text { tambatan } \\
371 \mathrm{~m}\end{array}$ \\
\hline 2. & Terminal penumpang & $1250 \mathrm{~m}^{2}$ & $2322 \mathrm{~m}^{2}$ & $2656 \mathrm{~m}^{2}$ \\
\hline 3. & Lapangan penumpukkan & $8600 \mathrm{~m}^{2}$ & $22534 \mathrm{~m}^{2}$ & $29875 \mathrm{~m}^{2}$ \\
\hline 4. & - Gudang Lini I & $3050 \mathrm{~m}^{2}$ & $5898 \mathrm{~m}^{2}$ & $7734 \mathrm{~m}^{2}$ \\
& - Gudang Lini II & $3010 \mathrm{~m}^{2}$ & $8847 \mathrm{~m}^{2}$ & $1601 \mathrm{~m}^{2}$ \\
\hline 5. & Alat bongkar muat: & 1 unit & 2 unit & 2 unit \\
& - shore crane & 3 unit & 2 unit & 3 unit \\
& - forklift & 4 unit & 19 unit & 26 unit \\
& - tronton & 40 unit & 27 unit & 35 unit \\
\hline
\end{tabular}

\section{Kesimpulan}

Dari hasil analisis terhadap arus lalu lintas laut dan pengaruhnya terhadap kebutuhan fasilitas pelabuhan Yos Sudarso, dapat disimpulkan bahwa:

a. Hasil analisis regresi menunjukkan tingkat pertumbuhan penduduk, PDRB (produk domestik regional bruto) dan pendapatan per kapita berpengaruh pada jumlah arus penumpang, kapal dan barang di pelabuhan Yos Sudarso Ambon.

b. Data arus penumpang, kapal dan barang terlihat ada kecenderungan meningkat, ini mengindikasikan bahwa terjadi peningkatan beban bongkar muat barang, menaik turunkan penumpang dan kunjungan kapal yang berdampak pada kinerja dermaga dalam pelayanannya untuk tahun-tahun berikutnya, dimana kemungkinan besar akan terjadi peningkatan lagi.

c. Hasil perhitungan menunjukkan bahwa untuk kondisi jangka pendek, fasilitas pelabuhan perlu pengembangan. Pengembangan dapat dilakukan dengan memperluas area fasilitas maupun dengan peningkatan produktivitas bongkar muat menjadi dua kali lipat yang berpengaruh pada waktu tunggu kapal.

\section{Daftar Pustaka}

[1] Nasution, M.N. 2003. Manajemen Transportasi. Ghalia Indonesia. Jakarta.

[2] Sulaiman, W. 2002. Statistik Non Parametrik, Contoh Kasus dan Pemecahannya dengan SPSS. ANDI. Yogyakarta

[3] Santosa, P.B, dkk. 2005. Analisis Statistik dengan Microsoft Exel dan SPSS. ANDI. Jakarta

[4] Anonymous. 1978. Port Development. UNCTAD. New York.

[5] Triatmodjo, B. 2009. Perencanaan Pelabuhan. Beta Offset. Yogyakarta

[6] Suranto, S.E. 2004. Manajemen Operasional Angkutan Laut dan Kepelabuhanan serta Prosedur Impor Barang. PT. Gramedia Pustaka Utama. Jakarta 